\title{
REACTIVE POLYARTHRITIS IN TUBERCULOSIS: A CASE OF TUBERCULOUS RHEUMATISM (PONCET'S DISEASE)
}

\author{
Sachin N. Solanke ${ }^{1}$, Parag R. Kulkarni²
}

\section{HOW TO CITE THIS ARTICLE:}

Sachin N. Solanke, Parag R. Kulkarni. "Reactive Polyarthritis in Tuberculosis: A Case of Tuberculous Rheumatism (Poncet's Disease)". Journal of Evolution of Medical and Dental Sciences 2014; Vol. 3, Issue 29,

July 21; Page: 8023-8026, DOI: 10.14260/jemds/2014/3006

ABSTRACT: SUMMARY: Atypical presentations of tuberculosis are known. We present here a case of reactive polyarthritis due to tuberculosis. Patient was treated with four drugs anti Tuberculous regime which led to complete resolutions of symptoms.

INTRODUCTION: Tuberculosis (TB) is a major public health problem. It ranks second leading cause of death from infectious diseases. In year 2012 estimated global annual incidence of TB was 8.6 million cases, out of which 2.3 million were occurred in India and 1.3 million death occurred globally.1,2

Atypical presentation of TB can be contributing factor for delayed diagnosis, morbidity and mortality. ${ }^{3}$ We reporting here case of inflammatory polyarthritis turned out to be reactive polyarthritis due to tuberculosis. So high index of suspicion and early treatment led to successful outcome.

CASE SUMMARY: A 36years old female presented to an outpatient clinic with complains of low grade fever, loss of appetite and painful swelling of both ankles, wrist, elbow, shoulder joints, and small joints of the fingers. There were no respiratory symptoms, no symptoms of urinary tract infection or sexually transmitted infections. There was no history of malar rash, oral ulcers, and rash. There was no significant lymphadenopathy or erythema nodosum. Clinical examination revealed low body weight 45kgs, mild pallor, Pulse rate $92 / \mathrm{min}$, Blood pressure 100/70 mmHg, Body Temperature 39.1 ${ }^{\circ}$ C. Her cardiac and respiratory examination was within normal limits. Her haemoglobin was 10.8 gm $\%$ and microcytic hypochromic picture in peripheral smear.

Total leukocyte count of 8200/cumm. DLC showing $55 \%$ neutrophils, $41 \%$ lymphocytes, 2\% eosinophil, $2 \%$ monocytes. ESR was $40 \mathrm{~mm} / \mathrm{Hr}$. Serum Uric acid $4.6 \mathrm{mg} \%$ and negative for HIV 1 and 2 antibodies. Urine routine examination was normal. Chest X-ray revealed normal. Rheumatoid Factor, ASO titre, antinuclear antibody, anti CCP antibodies were negative. X-ray of involved joints showed soft tissue swelling. Mantoux test was positive $(12 \mathrm{x} 12 \mathrm{mms})$. MRI of left ankle joint (severely involved) showed inflammatory arthritis.

The patient was started on INH 300mg, Rifampicin $450 \mathrm{mg}$, pyrazinamide $1.5 \mathrm{gm}$, Ethambutal $800 \mathrm{mg}$ daily. After 3 weeks of treatment joint pain and swelling reduced significantly and after 6 weeks of treatment patient completely became free of joint pain.

DISCUSSION: Poncet ${ }^{4}$ described the clinical features of tuberculous rheumatism in 1987. Poncet's disease is used to indicate as an aseptic polyarthritis, presumably reactive arthritis, developing in the presence of TB elsewhere. ${ }^{5}$ 
It has been postulated that Poncet's disease and erythema nodosum could be different immunological expressions of the body to different fractions of tubercle bacillus. Another possibility is thought to be an arthritogenetic factor precipitating the condition. Autoimmunity has also been suggested as a cause. ${ }^{6}$

It is well known that tuberculous septic arthritis in which M. tuberculosis can be isolated from the joint. But active TB may be complicated by a sterile Reactive arthritis (ReA) which is less known and therefore often missed. Patients often respond quickly to the treatment of tuberculous reactive arthritis in Poncet's disease compared with tuberculous septic arthritis. ${ }^{7,8}$

Even in countries with high TB prevalence, diagnosis remains challenging due to atypical presentation of Poncet's disease. Poncet's disease showed wide atypical presentation such as only $6 \%$ patients had erythema nodosum, suggest decreased prevalence of erythema nodosum with active primary TB. $30 \%$ of patients showed some features of oligoarthritis and the rest, polyarthritis. ${ }^{9}$

In this patient, synovial fluid examination was not done since there was no clinical indication of joint effusion or joint destruction. The diagnosis of Poncet's disease were made based on clinical suspicion, especially when synovial fluid examination was not possible. ${ }^{9}$ In the study of review of 50 cases Kumar et al diagnosed 2 cases on clinical basis only. 10

The present case, search for other causes of polyarthritis did not succeed, tuberculin test was positive and also MRI showed inflammatory arthritis. So we suspected Poncet's disease. Subsequent improvement of arthritis on starting anti tuberculous drugs conformed the diagnosis of tuberculous rheumatism.

CONCLUSION: Diagnosis of TB in some patients delayed because of atypical presentation. Even though it is not possible to come to conclusive diagnosis of Poncet's disease, immunological reactions such as reactive arthritis even without respiratory symptoms should alert physician to search for TB. Thus performing relevant examination and investigations may help to diagnose and treat appropriately before developing the complications.

\section{REFERENCES:}

1. World Health Organisation. Global Tuberculosis Control: WHO Report 2013. Geneva: WHO Press. 2013.

2. TB India .Revised National TB Control Programme annual status report; 2014.

3. Chang CT, Esterman A. Diagnostic delay among pulmonary tuberculosis patients in Sarawak: a cross-sectional study. Rural and Remote Health. 2007; 7: 1-8.

4. Poncet A. De la polyarthrite tuberculous deformanteou pseudorheumatisme chronique tuberculeux. Congr Fr Chir; 1897, 2, 732.

5. Bocanegra TS. Infection: Mycobacterial, Brucella, fungal andparasitic arthritis. In: John $\mathrm{H}$ Klippel, Paul A Dieppe, eds. Rheumatology, second. London: Mosby, 1982; Chapter 46.4.4.

6. Dall L., Long L. Stanford J. Poncet's disease: Tuberculous rheumatism. Review of Infectious Diseases, Vol. II, No, 1, 1989, 105.

7. Ideguchi H, Ohno S, TakaseK and et al. A case of Poncet's disease (tuberculous rheumatism). Rheumatol Int. 2009; 29:1097-9. doi 10.1007/s00296-008-0795-1. 


\section{CASE REPORT}

8. Abdul aziz S, Almoallim H, Ibrahim A, Samannodi M, Shabrawishi M, Meeralam Y, et al. Poncet's disease (reactive arthritis associated with tuberculosis): retrospective case series and review of literature. Clin Rheumatol. 2012; 31:1521-8.

9. Kroot EJA, Hazes JMW, Colin EM, Dolhain RJEM. Poncet's disease: reactive arthritis accompanying tuberculosis. Two case reports and a review of the literature. Rheumatology. 2007; 46: 484-9.

10. Kumar PD, Sasidharan PK, Paul BJ, Tharian G, Bhargavan PV. Poncet's disease. J Assoc Physicians India 1993; 41: 400.

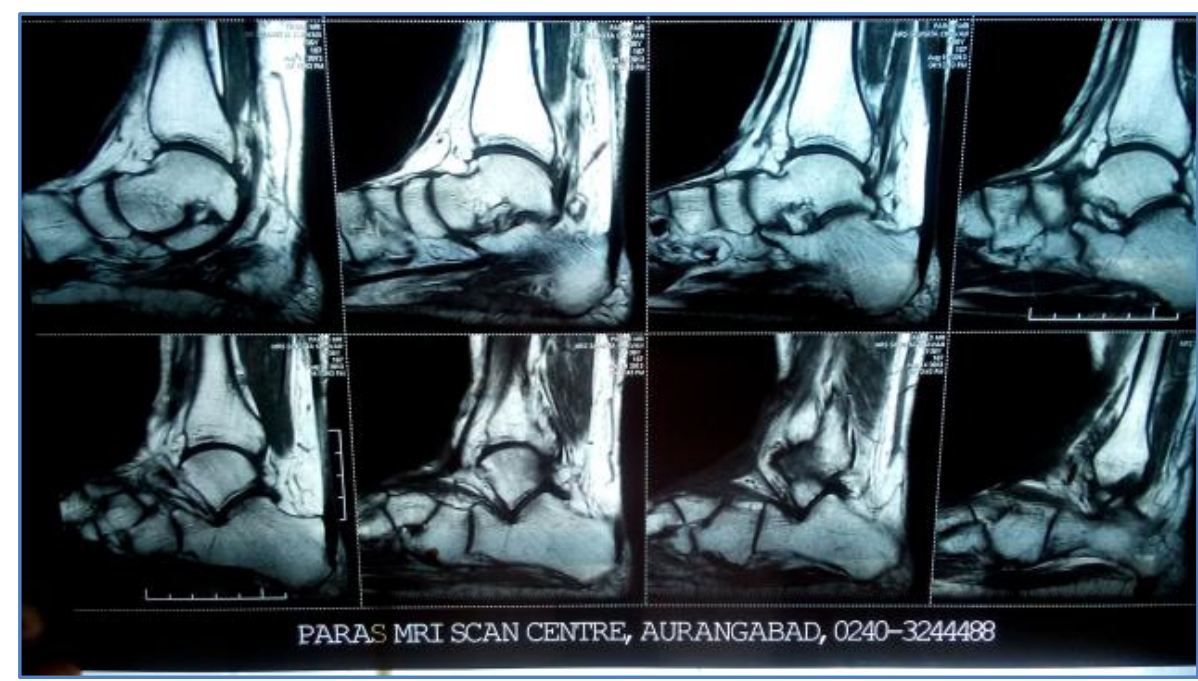

Fig. 1: MRI of Left Ankle

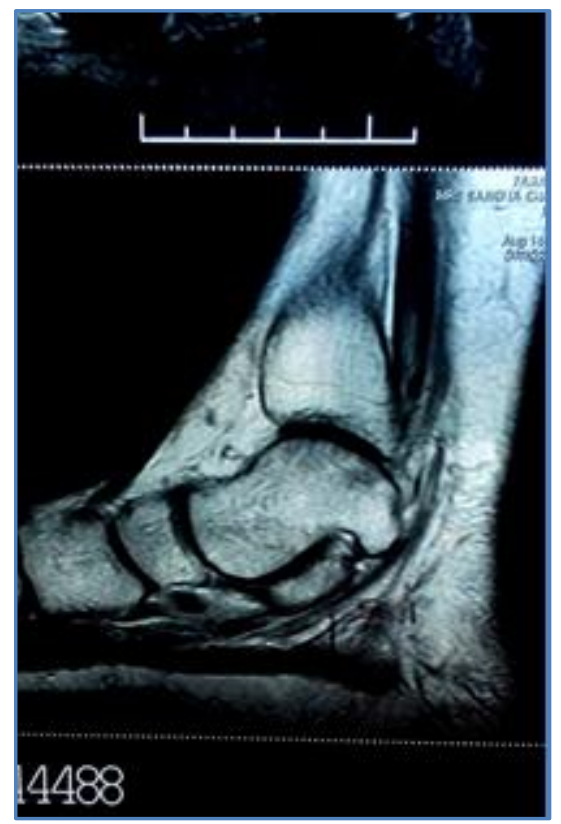

Fig. 2: MRI of Left Ankle 


\section{CASE REPORT}

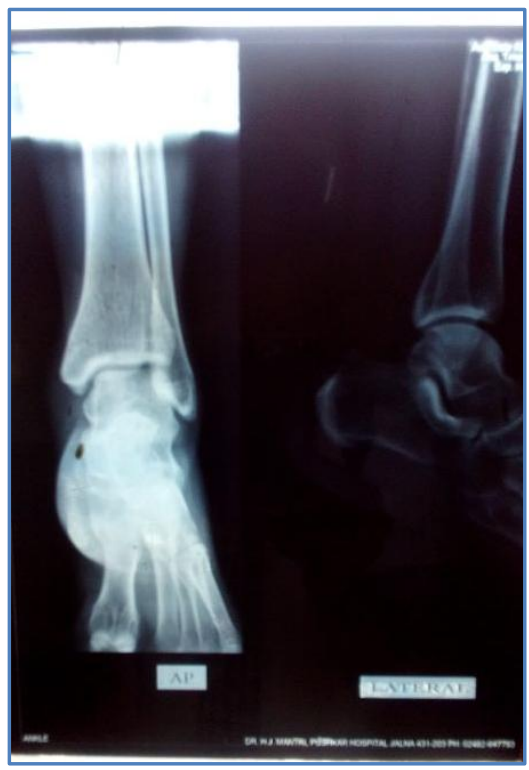

\section{Fig. 3: X-ray left Ankle AP}

\section{AUTHORS:}

1. Sachin N. Solanke

2. Parag R. Kulkarni

\section{PARTICULARS OF CONTRIBUTORS:}

1. Assistant Professor, Department of Medicine, Government Medical College and Hospital, Aurangabad, Maharashtra, India.

2. Consultant Orthopaedician, Department of Orthopaedics, Kulkarni Clinic, Roshan Gate Aurangabad.

\section{NAME ADDRESS EMAIL ID OF THE} CORRESPONDING AUTHOR:

Dr. Sachin N. Solanke, Assistant Professor, Department in Medicine, Govt. Medical College and Hospital, Aurangabad-431001, Maharashtra, India.

Email: drsachinsolanke@gmail.com

Date of Submission: 10/07/2014.

Date of Peer Review: 11/07/2014.

Date of Acceptance: 12/07/2014.

Date of Publishing: 16/07/2014. 